\title{
Biotechnological Advances for Animal Nutrition and Feed Improvement
}

\author{
Bimrew Asmare* \\ College of Agriculture and Environmental Sciences, Bahir Dar University, P.O.Box 79, Bahir Dar, Ethiopia \\ *Corresponding author: imasm2009@gmail.com
}

Received March 03, 2014; Revised March 23, 2014; Accepted May 06, 2014

\begin{abstract}
Shortage of animal feed in most developing countries and the increasing cost of feed ingredients mean that there is a need to improve feed utilization. Although developing countries accommodate a majority of the world's people, there is a risk that biotechnology research and development may by-pass their requirements. However, there are beginnings of using biotechnology in animal production particularly animal nutrition these days. The advances of biotechnology in recent years allowed the use of non-toxic fungi to improve fibrous feeds like straw or poor quality roughages. In particular, the white rot fungi have been used because of their ability to delignify the plant material. In addition to antibiotics, a wide variety of feed additives, are known to modify rumen fermentation. They include components that can reduce methanogenesis, enhance propionic acid production, reduce protein degradation, improve microbial protein synthesis and inhibit protozoa. Among such additives are antibiotics, microbes, and specific substrates like oligosaccharides. In addition, effective enzyme preparations can now be produced in large quantities and relatively inexpensively. Therefore, supplementation of the diet as a means of improving nutritive value is becoming commonplace. The ultimate goal of using biotechnology in animal nutrition is to improve the plane of nutrition through increasing availability of nutrients from feed and to reduce the wastage of the feed. Their potential in developing countries is less than in developed countries, mainly because the successful application usually requires better feed quality and management.
\end{abstract}

Keywords: biotechnology, defaunation, forage, feed additives

Cite This Article: Bimrew Asmare, "Biotechnological Advances for Animal Nutrition and Feed Improvement." World Journal of Agricultural Research, vol. 2, no. 3 (2014): 115-118. doi: 10.12691/wjar-2-3-5.

\section{Introduction}

Demand for livestock products is increasing because of the increasing human population, growth in income and urbanization [1] in these parts of the globe. For example, total meat production in the developing world tripled between 1980 and 2002, from 45 to 134 million tons. Demand for meat will grow only $0.6 \%$ in developed countries compared with an annual increase of $2.8 \%$ in developing countries. Most food of animal origin consumed in developing countries is currently supplied by small-scale, often mixed crop-livestock family farms or by pastoral livestock keepers [2]. Hence, productivity of animals in developing countries will need to be substantially increased in order to satisfy increasing consumer demand, to more efficiently utilize scarce resources and to generate income for a growing agricultural population [2]. Conventional methods of livestock improvement have been used in the past served the purpose of increasing livestock productivity. However, these options can no longer sustain production; consequently new intensive techniques including biotechnology are now required to augment productivity. Modern biotechnology has the potential to provide new opportunities for achieving enhanced livestock productivity in a way that alleviates poverty, improves food security and nutrition and promotes sustainable use of natural resources [3]. This paper reviewed the common application of biotechnology in animal nutrition and feeding, limitations and future implications.

\section{Biotechnology for Fibrous Feeds Improvement}

Fibrous feeds of low digestibility comprise the major proportion of feeds accessible to most ruminants under smallholder situations in developing countries [4]. It is well known that some micro-organisms, including cellulose enzymes from anaerobic bacteria and white rot fungi (Pleurotus ostreatus) can degrade lignin in the cell walls. Several fungal strains have been used for lignocellulosic hydrolysis such as Asprigullus niger, A. terreus, Fusarium moniliforme and Chaetomium celluloyticum [5]. However, among many species of fungi white rot fungi have been reported to be suitable for treatment of roughages so far. As in [6], the white rot fungi have the capacity to attack lignin polymers, open aromatic rings and release low molecular weight fragments. Significant results were reported in [7] for CP of maize cob treated with fungi species (Pleurotus pulmonarius and Pleurotus sajor-caju). 
It must be remembered, however, that whatever organism is grown on the roughage must obtain its energy from the roughage itself [3]. In general, the organisms that suit for this purpose must have a number of special properties. They must be capable to grow on a wide range of carbon sources, have high growth rates to minimize the size of the fermentation system and have a high efficiency in converting of substrate to biomass with high protein content.

Another indirect approach to the enhancement of fiber digestion in ruminants is through modification of silage inoculants. In silages containing low carbohydrate contents, inclusion of amylase, cellulase or hemicellulase enzymes has been shown to increase lactic acid production by releasing sugars for growth of lactobacilli. Thus, inoculation of silage bacteria genetically modified to produce such enzymes has been proposed to obtain better ensiling and/or pre-digest the plant material in order to lead to better digestibility in the rumen. As in [8], recombinant Lactobacillus plantarum, a species used as silage starter, were constructed to express alphaamylase, and cellulase or xylanase genes. The competitive growth and survival of such modified lactobacilli in silage has been reported by other workers [9], although the impact on silage digestibility has not been studied.

\section{Biotechnology in Forage Breeding}

Genetically engineered forage crops, with a range of potential benefits for production, the environment and human health, have been developed [10]. Genetically engineered forage crops are genetically modified using recombinant DNA technology with the objective of introducing or enhancing a desirable characteristic in the plant or seed. These transgenic forage crops are aimed at offering a range of benefits to consumers, as well as developers and producers. Products to be consumed by humans, derived from animals fed on transgenic forage crops, are not themselves transgenic. Thus food products derived from animals fed on transgenic forage crops offering human health benefits may receive different levels of support from the public than the currently available set of transgenic food crops [10].

It is known that forage legumes are comparatively low in sulphur-containing amino acids and their availability to ruminants is further adversely affected during rumen digestion [11]. This leads to the reduction of the optimum for animal growth level of essential amino acids. Plant genetic modification with genes encoding for a sulphur amino acid-rich proteins, resistant to rapid rumen degradation can compensate this deficiency. Agronomic researchers around the globe are currently using recombinant DNA technology to create new and altered species of plants.

As in [3] plants in order to survive insect, fungal and bacterial attack have developed secondary compounds which detract from these organisms colonizing the leaf tissues. In another study, researchers at the Noble Foundation have been successful in manipulating lignin composition and levels in alfalfa and other forages to improve their digestibility and the conversion of biomass to biofuels. Some shrubs and trees respond to leaf damage as occurs by grazing and produce greater quantities of secondary compounds which often make them inedible. Anti-nutritive factors in plant tissues include protease inhibitors, tannins, phytohaemagglutinins and cyanogens in legumes, and glucosinolates, tannins and sanapine in oilseed rape (Brassica napus) and other compounds in feeds belonging to the Brassica group.

Studies [12] showed that the inclusion of genetically modified feed ingredients in dairy cow diets did not affect feed intake or milk production. These crops are being engineered with substantial changes in their content of major components (e.g., proteins, amino acids, oils, fatty acids, starches, sugars, fiber) or minor components (e.g., vitamins, minerals, enzymes). As these improved feed crops are designed and intended to be different from nonbiotech varieties, they are not expected to be substantially equivalent.

\section{Biotechnology Products as Feed Additives}

Feed additives are materials that are administered to the animal to enhance the effectiveness of nutrients and exert their effects in the gut [13]. Feed additives include antibiotic, enzymes propbiotics and prebiotics [14].

\subsection{Antibiotics}

Antibiotics are antimicrobial pharmaceutical, usually of plant or fungal origin and are also synthesized in the laboratory [13]. Although the primary use of antibiotics is in the treatment of infections, certain antibiotics are used as feed additives in order to improve growth and feed conversion efficiency. Among antibiotic groups are ionophores [14] which are ion-bearing compounds, which surrounds cations so that the hydrophilic ion can be shuttled across hydrophobic cellular membranes to defeat the normal concentration gradient essential in living cells [13]. Ionophores display diverse structures and profiles of cation selectivity. For example, valinomycin is a cyclic peptide which binds potassium, while monensin is a carboxylic ionophore which displays a binding preference for sodium. Both can act as antibiotics. Ionophores are used in ruminant animals like cattle to improve feed efficiency by shifting rumen fermentation towards the production of more propionic acid, which can be used by the animal and less methane, which is lost. Ionophores hereby change the pattern of rumen microorganisms, reducing the production of acetate, butyrate and methane, and increasing the proportion of propionate $[14,15])$. Since methane is a waste product, the efficiency of rumen activity is improved. Ionophores also reduce the total mass of bacteria and thereby decrease the amount of dietary protein degraded. Avilomycin is licensed for use in pigs, broiler chickens and turkeys. Salinomycin is an ionophore available for use in pigs and also used to prevent coccidiosis in broiler chickens [13].

As indicated in [15], ionophores have general metabolic role within the animal through improving production efficiency by providing a competitive advantage for certain microbes at the expense of others. In general, the metabolism of the selected microorganisms favors the host animal. In another report, broilers receiving the diet supplemented with antibiotic had significantly lower total 
aerobic bacterial counts in the small intestines compared to those on the other dietary treatments [16]. The combined supplementation of the antibiotic and enzyme resulted in a significantly lower $E$. coli concentration in the small intestines compared to the basal diet and the other dietary treatments.

\subsection{Enzymes}

As a result of advances in biotechnology, more effective enzyme preparations can now be produced in large quantities and relatively inexpensively [14]. Therefore, supplementation of the diet as a means of improving nutritive value is becoming commonplace. The enzymes used as food additives act in a number of ways. According to studies [13], enzymes are mainly used in the diets of non-ruminants but are also added to ruminant diets. Their main purpose is to improve the nutritive value of diets, especially when poor-quality, and usually less expensive, ingredients are incorporated. Common example of enzymes is use of phytase feed enzyme in monogastric diets. Phytase feed enzymes have more general application as their substrate is invariably present in pig and poultry diets and their dietary inclusion economically generates bio-available phosphorous and reduces the phosphorous load on the environment. The prohibition of protein meals of animal origin, which also provide phosphorous, has accelerated the acceptance of phytase feed enzymes in certain countries [13].

Amino acid digestibility may also be improved with phytase supplementation. In a study with finishing pigs, as in [17], the digestibility of all amino acids except proline and glycine increased linearly as phytase supplementation increased. In ruminant nutrition, enzymes improve the availability of plant storage polysaccharides (e.g. starch), oils and proteins, which are protected from digestive enzymes by the impermeable cell wall structures. Thus, cellulases can be used to break down cellulose, which is not degraded by endogenous mammalian enzymes. Enzymes are essential for the breakdown of cell-wall carbohydrates to release the sugars necessary for the growth of the lactic acid bacteria. Supplementation of a wheat by-product diet with cellulase increased the ileal digestibility of non-starch polysaccharides from 0.192 to 0.359 and crude protein from 0.65 to 0.71 [14].

\subsection{Probiotics and Prebiotics}

Probiotics are feed supplements that are added to the diet of farm animals to improve intestinal microbial balance [13]. In contrast to the use of antibiotics as nutritional modifiers, which destroy bacteria, the inclusion of probiotics in foods is designed to encourage certain strains of bacteria in the gut at the expense of less desirable ones [14]. Besides, these microorganisms are responsible for production of vitamins of the $\mathrm{B}$ complex and digestive enzymes, and for stimulation of intestinal mucosa immunity, increasing protection against toxins produced by pathogenic microorganisms. In ruminants, they are more effective in controlling the diseases of the gastrointestinal tract of young animals, as there is no complication of the rumenmicro-flora. The initial colonization of the small intestine is from the dam's microflora and the immediate surroundings, and usually includes streptococci, E. coli and Clostridium welchii. When milk feeding commences, the lactobacilli become the predominant bacteria present. Calf probiotics contain benign lactobacilli or streptococci and are likely to be valuable only when given to calves that have suffered stress or have been treated with antibiotics that have destroyed the natural microflora [13]. Addition of probiotics to the diet produces variable benefit, depending on whether the animals are in poor health. It is also difficult to determine which bacterial species would be beneficial in any given circumstance. Probiotics have sometimes been found to be beneficial in protecting pigs from infectious diseases. Lactic acid bacteria isolated from the gastrointestinal tract of pigs, such as Enterococcus faecium and L. acidophilus, can inhibit enteric indicator strains, such as Salmonella enteritidis, S. cholera suis, $S$. typhimurium and Yersinia enterocolitica. Dry yeast (Saccharomyces cerevisiae) has the advantage over bacterial probiotics that it is more tolerant of extreme $\mathrm{pH}$ and environmental conditions. Probiotic use is subject to extensive legislation designed to protect farm animals and consumers. In adult ruminants yeasts may be used as probiotics to improverumen fermentation [13]. The most common prebiotics are oligosaccharides, which are nondigestible carbohydrates.

\section{Defaunation in Ruminants}

Protozoa, unlike bacteria, are not vital for the development and survival of the ruminant host, and their elimination (defaunation), although producing a less stable rumen environment, has been found to reduce gaseous carbon and nitrogen losses [13]. It has been established that ruminants can survive with or without these organisms; however, manipulating their population may affect protein metabolism in the rumen [18].

The control of the rumen protozoal population by inhibition compounds would seem attractive because their eukaryotic cell nature would allow them to be susceptible to a number of compounds that would have little or no effect on the prokaryotic bacterial cells [14]. However, the rumen methanogenic micro-organisms could also be sensitive because of their archaebacteriai cell nature and loss of these hydrogen-gas-utilizing methanogenic organisms would drastically disrupt the entire rumen fermentation system. The metabolism of other bacterial species would also have to be genetically engineered to provide a hydrogen sink. One possibility would be to engineer Eubacterium limosum, a relatively numerically minor species in the rumen, to preferentially form acetate and butyrate from HP and carbon dioxide.

In another study [19], defaunation did not decrease total free amino acid concentrations in ruminal fluid, but it altered the profile of free amino acids. Although defaunation increased ruminal bacterial numbers, no increases in total microbial CP or OM concentrations in ruminal contents were observed. As indicated in [20], for sheep based forage diets as protozoal population reduced (84\%), the degradability of the dry matter at $24 \mathrm{~h}$ also increased significantly. An important implication of this study is the possibility of developing a practical way to maintain a reduced number of protozoa in ruminants while at the same time being a source of nutrients. 


\section{Conclusion}

Biotechnology is a support for various fields of agricultural production and processing. It offers a range of tools to advance our understanding, management and use of crop and livestock resources for different social and economic benefits of man. Biotechnology in animal production in developing countries has been applied only in a few areas such as conservation, animal improvement, healthcare and augmentation of feed resources. Adopting biotechnology has benefitted by in animal improvement and economic returns to the livestock entrepreneurs and small producers. Fibrous feeds, including crop residues, of low digestibility constitute the major proportion of feeds available to most ruminants under smallholder situations in developing countries. The associated low productivity can be overcome to some extent by several means, among which are: balancing of nutrients for the growth of rumen microflora thereby facilitating efficient fermentative digestion and providing small quantities of by-pass nutrients to balance the products of fermentative digestion, enhancing digestibility of fibrous feeds through treatment with alkali or by manipulating the balance of organisms in the rumen and genetic manipulation of rumen microorganisms, currently acknowledged as potentially the most powerful tool for enhancing the rate and extent of digestion of low quality feeds. Rumen micro-organisms can also be manipulated by adding antibiotics as feed additives, fats to eliminate or reduce rumen ciliate protozoa (defaunation), protein degradation protectors, methane inhibitors, buffer substances, bacteria or rumen content and/or branched chain volatile fatty acids.

It can be concluded that there are several potential opportunities for improving the efficiency of ruminant digestion and possibilities for utilising a wider range of feeds than is currently possible. Modification of rumen microbial population is one such opportunity. However, technical difficulties associated with making genetic modifications to individual species of rumen bacteria hinder progress in this area. Additives to animal nutrition, such as enzymes, probiotics, single-cell proteins and antibiotics in feed, are already widely used in intensive production systems worldwide to improve the nutrient availability of feeds and the productivity of livestock. Gene-based technologies are being increasingly used to improve animal nutrition, through conservation of feed stuff in a form that keep or even improve its nutrients e.g. silage, biological treatment with microorganisms or through modifying the digestive and metabolic systems of the animals, i.e. modifying rumen ecosystem, to enable them to make better use of the available feeds The use of biotechnology to improve postingestion quality of fibrous forages is on the verge of delivering practical benefits to ruminant production system. The microbial flora of the rumen can be successfully manipulated if such manipulations are adding exogenous fibrolytic enzymes to ruminants can potentially improve cell wall digestion and the efficiency of feed utilization.

\section{References}

[1] Thornton, P.K., (2010). Review livestock production: recent trends, future prospects. Phil. Trans. R. Soc. B, 365: 2853-2867.

[2] John Ruane, Maria Zimmermann, (2001).Report of the first six email conferences of the FAO Electronic Forum on Biotechnology in Food and Agriculture.

[3] Leng R.A., (1991). Application of biotechnology to nutrition of animals in developing countries. FAO, Animal Production And Health Paper 90.

[4] Lebbie S.H.B. and Kagwini E., (1996). Small Ruminant Research and Development in Africa. Proceedings of the Third Biennial Conference of the African Small Ruminant Research Network, UICC, Kampala, Uganda, 5-9 December 1994. ILRI (International Livestock Research Institute) Nairobi, Kenya. 326 pp.

[5] Kim, J. H., M. Hosobuchi., Kishimoto., T. Seki., H.Taguchi and D. D. Y. Ryu, (1985). Cellulose production by solid state fermentation system. Biotech. And Bioenge. 27:1450-1454.

[6] Zadrazil, F; Puniya, A.K. Singh, K., (1995). Biological upgrading of feed components. Biotechnology in Animal Feeding. Pp 55-69. (Eds.) Wallae, R. J., Chesson, A. and Weinheim, V. C. H.

[7] Akinfemi A, O A Adu and F Doherty, (2009). Assessment of the nutritive value of fungi treated maize cob using in vitro gas production technique. Livestock Research for Rural Development, Volume 21, Number 11, November 2009. ISSN 0121-3784.

[8] Scheirlinck T., DeMeutter J., Arnaut G., Joos H., Claeyssens M., Michiels F.,(1990). Cloning and xpression of cellulase and xylanase genes in Lactobacillus plantarum, Appl. Microbiol. Biotechnology. 33: 534-541.

[9] Sharp R., O’Donnell A.G., Gilbert H.J., Hazlewood G.P., (1992) Growth and survival of genetically manipulated Lactobacillus plantarum in silage, Appl. Environ. Microbiol. 58: 2517-2522.

[10] Spangenberg G, Kalla R, Lidgett A, Sawbridge T, Ong EK, John U,(2001). Transgenesis and genomics in molecular breeding of forage plants. Retrieved 16 January, 2014, from the World Wide Web: ttp://www.regional.org.au/au/asa/2001/plenery/6/spangenberg.htm.

[11] Croissant G., Meton B., Miller D., Kellog W., (1976). New Mexico State Univ.Agricult. Experiment station, Las Cruces.

[12] Phipps R. H., A. K. Jones, A. P. Tingey,and S. Abeyasekera (2005). Effect of Corn Silage from an Herbicide-Tolerant Genetically Modified Variety on Milk Production and Absence of Transgenic DNA in Milk. J. Dairy Sci. 88: 2870-2878.

[13] Fuller, R., (1989). Probiotics in man and animals. A review. Journal of Applied Bacteriology, 66, 365-378.

[14] McDonald P., R. A. Edwards, J. F. D. Greenhalgh, C. A. Morgan, L. A. Sinclair and R. G. Wilkinson, (2010). Animal Nutrition. Pearson Books.

[15] McGuffey R. K., L. F. Richardson, and J. I. D. Wilkinson, (2001). Ionophores for Dairy Cattle: Current Status and Future Outlook. J. Dairy Sci. 84 (E. Suppl.): E 194-E 203.

[16] Sarica S., A. Ciftci, E. Demir, K. Kilinc and Y. Yildirim, (2005). Use of an antibiotic growth promoter and two herbal natural feed additives with and without exogenous enzymes in wheat based broiler diets. South African Journal of Animal Science 2005, 35 (1)

[17] Zhang, Z., and E.T. Kornegay, (1999). Phytase effects on ileal amino acid digestibility and nitrogen balance in finishing pigs fed a low-protein plant-based diet. J. Anim. Sci. 77 (1): 175.

[18] Wael G. Fahmy, Ali O. Bahaa, Michael R. Murphy, Siyabulela W. Nombekela, Robert N. Corley, III, and Jin S. Zhu.(1998). Effect of Defaunation and Amino Acid Supplementation on Growth and Amino Acid Balance in Sheep. University of Illinois Extension, available http://www.livestocktrail.illinois.edu/dairynet/paperDisplay.cfm? ContentID=238 accessed on 13/03/2013.

[19] Hsu JT, Fahey Jr. GC, Merchen NR, Mackie RI (1991). Effects of Defaunation and Various Nitrogen Supplementation Regimens on Microbial Numbers and Activity in the Rumen of Sheep. J. Anim. Sci. 69: 1279-1289.

[20] Diaz A, Avendano M and Escobar A, (1993). Evaluation of Sapindus saponaria as a defaunating agent and its effects on different ruminal digestion parameters. Livestock research for rural development. Volume 5, No. 2. 